\title{
1 Homogenization of lake cyanobacterial communities over a \\ 2 century of climate change and eutrophication
}

3

4 Marie-Eve Monchamp ${ }^{1,2 *}$ me.monchamp@gmail.com, Piet Spaak ${ }^{1,2}$, Isabelle Domaizon ${ }^{3}$, 5 Nathalie Dubois ${ }^{4,5}$, Damien Bouffard ${ }^{6}$, Francesco Pomati ${ }^{1,{ }^{2 *}}$ francesco.pomati@eawag.ch

$6 \quad{ }^{1}$ Eawag, Swiss Federal Institute of Aquatic Science and Technology, Department of Aquatic

7 Ecology, 8600 Dübendorf, Switzerland;

$8 \quad{ }^{2}$ Swiss Federal Institute of Technology (ETH) Zürich, Institute of Integrative Biology, 8092

9 Zürich Switzerland;

$10{ }^{3}$ INRA, Université de Savoie Mont Blanc, UMR CARRTEL, 74200, Thonon-les-bains, 11 France;

$12{ }^{4}$ Eawag, Swiss Federal Institute of Aquatic Science and Technology, Department of Surface 13 Waters Research \& Management, 8600 Dübendorf, Switzerland;

$14{ }^{5}$ Swiss Federal Institute of Technology (ETH) Zürich, Department of Earth Sciences, 8092

15 Zürich, Switzerland;

$16{ }^{6}$ Eawag, Swiss Federal Institute of Aquatic Science and Technology, Department of Surface

17 Waters Research \& Management, 6047 Kastanienbaum, Switzerland

18 * Corresponding authors:

19 Mailing address: Eawag, Department of Aquatic Ecology, Überlandstrasse 133, 8600

20 Dübendorf, Switzerland.

21 Phone: +4158765 5410

This document is the accepted manuscript version of the following article: Monchamp, M. E., Spaak, P., Domaizon, I., Dubois, N., Bouffard, D., \& Pomati, F. (2018). Homogenization of lake cyanobacterial communities over a century of climate change and eutrophication. Nature Ecology \& Evolution, 2, 317-324. https : //doi .org/10.1038/s41559-017-0407-0 


\section{Main text}

Human impacts on biodiversity are well recognized, but uncertainties remain regarding patterns of diversity change at different spatial and temporal scales. Changes in microbial assemblages are, in particular, not well understood, partly due to the lack of community composition data over relevant scales of space and time. Here, we investigated biodiversity patterns in cyanobacterial assemblages over a century of eutrophication and climate change by sequencing DNA preserved in the sediments of 10 European peri-Alpine lakes. We found species losses and gains at the lake scale, while species richness increased at the regional scale over the past $\sim 100$ years. Our data show a clear signal for beta diversity loss, with the composition and phylogenetic structure of assemblages becoming more similar across sites in the most recent decades, as have the general environmental conditions in and around the lakes. We attribute patterns of change in community composition to raised temperatures affecting the strength of the thermal stratification and, as a consequence, nutrient fluctuations, which favoured cyanobacterial taxa able to regulate buoyancy. Our results reinforce previous reports of human-induced homogenization of natural communities, and reveal how potentially toxic and bloom-forming cyanobacteria have widened their geographic distribution in the European temperate region.

Anthropogenic-induced alterations of ecosystems have contributed to reshaping biodiversity of natural communities globally ${ }^{1,2}$. Patterns of responses in local and regional biodiversity are regulated by mechanisms acting at different spatial and temporal scales ${ }^{3}$. Recent controversial debates on the accuracy of meta-analyses reporting biodiversity patterns have highlighted the sensitivity of the choice of the spatial and temporal scales, or geographical focus, for the final 
assessment of biodiversity loss or gain ${ }^{4-6}$. However, beta diversity loss over space or time (i.e. previously differentiated assemblages increasingly resembling one another) has been consistently reported ${ }^{4,7,8}$, supporting the hypothesis that human impacts can reduce environmental heterogeneity and thus increase homogenization of natural communities ${ }^{8,9}$, with potential impacts on ecosystems functioning and services ${ }^{10}$. Yet, this hypothesis remains untested in aquatic microbial assemblages, particularly photosynthetic microorganisms, whose biodiversity patterns are mostly unknown at large spatial and temporal scales.

Aquatic ecosystems are among the most sensitive to anthropogenic activities and biodiversity loss ${ }^{11}$. In lakes, combined warming and eutrophication (i.e. pollution caused by excessive discharge of nutrients) have favoured the dominance of cyanobacteria over eukaryotic phytoplankton ${ }^{12,13}$ due to eco-physiological adaptations, such as buoyancy regulation, fast growth rate, and adaptation to low light levels ${ }^{14,15}$. Cyanobacterial blooms create unfavourable conditions for other phytoplankton (e.g. low light conditions), as well as for organisms of higher trophic levels such as zooplankton and fish (e.g. anoxia) ${ }^{12,16}$. Over the past few decades, the frequency and severity of cyanobacteria-dominated communities have increased in lakes and reservoirs worldwide ${ }^{17}$ despite remediation measures applied at the regional and international scale ${ }^{14,18}$. Cyanobacterial blooms are often dominated by toxic species, and there is a global concern that climate change is promoting the geographic expansion of some potentially harmful taxa ${ }^{19-21}$ enhancing their dominance due to a combined effect of increasing nutrient load ${ }^{14,15}$.

The lack of long-term historical data (both biotic and abiotic), however, limits our understanding on how anthropogenic-induced changes have affected lake cyanobacterial taxa distribution and community composition over broad spatial and temporal scales. Studies in European peri-Alpine lakes have reported increasing occurrence of potentially harmful cyanobacteria such as Planktothrix rubescens ${ }^{22}$ and Dolichospermum lemmermannii ${ }^{21}$ over 
the last few decades that could be attributed to changes in local nutrient concentrations and a warmer climate. Yet, the relative influence of these environmental factors on the structure (diversity and composition) of cyanobacterial communities remains unclear.

In this study, we reconstructed trends in cyanobacterial community structure across 10 lakes of the European peri-Alpine region (see the map in Supplementary Fig. 1), and related diversity and compositional patterns to known long-term environmental drivers such as temperature and nutrients (Fig. 1). The average annual air temperature in the region investigated has increased over the past 150 years (Supplementary Fig. 2a), with an intensification of the trend since the 1980s. Increased air temperature raised surface lake water temperatures and led to a stronger (Fig. 1a, $\mathrm{R}^{2}$ adj. $=0.1683, p=2.568 \times 10^{-14}$ ) and longer (Supplementary Fig. 2b) thermal stratification. Over the twentieth century, peri-Alpine lakes also underwent evident shifts in phosphorus and nitrogen levels (Fig. 1b-c). The severity of change in nutrient loads varied from lake to lake, but the main shifts occurred roughly simultaneously across the whole peri-Alpine region. Total phosphorus (TP) increased rapidly around the 1950s to reach a maximum in the late 1960s - early 1970s (Fig. 1b). Mitigation of phosphorus discharges into lakes facilitated a rapid decrease of this nutrient, leading to the return of most lakes to TP concentrations that are similar to pre-eutrophication. On the contrary, nitrogen inputs have not been controlled and the concentration of this nutrient has increased over the twentieth century ${ }^{23,24}$ (Fig. 1c).

\section{Results \& Discussion}

We found that, along with climate change, eutrophication, and re-oligotrophication, the general environmental conditions across the study lakes have homogenized. The difference in mean annual air temperatures between the northern and the southern sides of the Alps decreased significantly over the last century (Fig. 1d). The annual mean TP concentrations across the lakes also became more uniform in the two most recent decades compared to the 
range of concentrations measured in earlier times (i.e. between 1950 and 1999; Fig. 1e). TP concentrations at present are equivalent to mesotrophic to eutrophic conditions in most lakes (Supplementary Table 1, Fig. $1 \mathrm{~b}$ and 1e). Conversely, the lakes display a wide range of $\mathrm{NO}_{3}$ $\mathrm{N}$ concentrations, which have remained relatively constant since the maximum of eutrophication (Fig. 1f).

To study compositional and phylogenetic changes of cyanobacterial communities across lakes and over time, we used DNA extracted from sediment cores (sedDNA) collected in the 10 lakes (Methods). SedDNA has been successfully used to elucidate changes in freshwater pelagic community composition of various plankton forms ${ }^{25}$, including cyanobacteria ${ }^{26-28}$. We reconstructed patterns in richness and community similarity by amplifying and sequencing part of the cyanobacterial 16S rDNA from dated sediment layers, and studied the dynamics of operational taxonomic units (OTUs), which represent groups of sequences with a minimum similarity of 97\%, within and between lakes (Methods). We have demonstrated previously that our reconstruction method in sedimentary archives provides an accurate description of cyanobacterial community composition, which is highly correlated to patterns obtained by historical microscopic observations of water samples ${ }^{28}$.

We found that the cyanobacterial community composition varied over time and across lakes (ranging from 9 to 52 OTUs, average $=25 \pm 10.5$ OTUs per lake) (Fig. 2a). Individual lake change in OTU richness over time was generally insignificant (at the $p=0.05$ level), with three exceptions: lakes Zurich, Lugano, and Hallwilersee that showed a significant increase. Overall, there was a significant temporal trend towards a slight increasing OTU richness across all lakes $\left(\mathrm{R}^{2}=0.18, p=0.000132 ; n=76\right.$; Fig. 2a). Species accumulation curves confirmed this trend across all lakes (Fig. 2b), suggesting a generalized gain of species at the peri-Alpine regional scale over the last century. A similar increase in taxa richness has been observed in meta-analysis studies across sites for communities that have been affected 
by anthropogenic disturbance, particularly post-disturbance successional changes in community composition ${ }^{6,729}$.

While reports of successful reconstructions of lake plankton community richness and composition based on relatively long DNA markers exist (e.g. ${ }^{30,31}$ ), possible biases due to DNA degradation with sediment age are of concern in palaeo-genetic studies ${ }^{32}$. We carefully inspected the dataset for the identification of patterns suggesting preferential DNA degradation (e.g. disappearance of OTUs in specific clades with sediment age), and we did not detect any significant bias. For example, cyanobacteria forming dormant cells (akinetes) were not relatively more represented or more diverse in older layers compared to more recent sediments. Our reconstructed data compare well with historical records of several of these well-studied lakes ${ }^{28}$, reporting, for example, the presence of the cyanobacterium P. rubescens in Lake Zurich, Baldeggersee, and Hallwilersee over the last two centuries ${ }^{33,34}$. In Lake Zurich, Pomati et al. have also shown an increase in phytoplankton richness over the past 30 years possibly due to reduction in phosphorus inputs combined with climate warmingmediated enhancement of resource heterogeneity over the water column ${ }^{35}$.

Temperature can have a direct metabolic effect on phytoplankton, but also indirect effects mediated by changes in the physical (strong thermal stratification leading to increased stability of the water column) and chemical lake state (nutrient recirculation due to mixing events). For example, the strength of thermal stratification in Lake Zurich has increased by $\sim 20 \%$ over the last three decades due to warming, and this impaired the frequency and magnitude of lake annual mixing ${ }^{36,37}$. Weaker mixing contributed to a reduction in the annual phytoplankton turnover in the latter lake ${ }^{38}$ due to limited winter resetting of the phytoplankton community, and favoured the dominance of the harmful cyanobacterium Planktothrix rubescens (order Oscillatoriales) ${ }^{36}$. We used linear mixed-effect models to study the potential environmental drivers of cyanobacterial OTU richness change in our dataset 
(Methods). The normalized maximal annual Schmidt Stability Index (SSI) and average annual TP concentrations were the only two significant and interacting variables $(p=0.002, \mathrm{n}=30)$ predicting natural log-transformed OTU richness (marginal $\mathrm{R}^{2}=0.614$; Fig. 2c). The fixed (SSI and TP) effects explained $61.4 \%$ of the variation in OTU richness, with no detectable additional effect of the random factor (lake). The remaining explanatory variables $\left(\mathrm{NO}_{3}-\mathrm{N}\right.$ and pairwise interactions) were not statistically significant $(p>0.2)$. Human activities in and around lakes, such as recreational boating and fish stocking, have intensified over the last century and might have contributed to the dispersal of cyanobacterial taxa across lakes of the same region. However, the successful establishment of an invading population is obviously strongly dependent on environmental conditions ${ }^{39,40}$.

The observed change in community structure co-occurred with an increase in the average similarity between lake communities (estimated at each decade based on unweighted Unifrac distance matrices - Methods) (Fig. 2d). This suggests a general homogenization of the phylogenetic community structure across lakes (i.e. loss of beta diversity), particularly over the few most recent decades. PERMANOVA (Methods) confirmed that the groups of communities sampled at each period have significantly different centroids $(p=0.01)$.

The proportion of weakly spatially distributed OTUs among lakes ("rare”; found in <25\% of lakes at a given period) decreased over the last century. Conversely, the proportion of OTUs common in multiple lakes (found in $>75 \%$ of lakes at a given period) increased about 4-fold between the 1950s (6\%) and the 1990s (24\%), after having remained relatively stable until the onset of lake re-oligotrophication in the late 1970s (Fig. 3). Our data suggest that changes in lake chemistry and physics might have promoted the dispersion of taxa that best fit the generalized contemporary environmental conditions.

The increase in similarity among cyanobacterial communities across lakes was in fact only driven by certain phylogenetic and taxonomic groups. Only three out of five 
cyanobacterial orders showed an increase in richness over the past century: Chroococcales, Nostocales, and Oscillatoriales (Fig. 4). This result indicates a higher gain in filamentous and colonial taxa able to regulate buoyancy relative to other cyanobacteria across peri-Alpine lakes. This observation is consistent with previous studies in lakes of the same region reporting phytoplankton compositional shifts in favour of colony-forming taxa due to climate warming and changes in nutrient concentrations ${ }^{27,36,41-43}$. The ability to regulate cells buoyancy allows Chroococcales, Nostocales and Oscillatoriales to float and sink periodically to access light (at the surface) and nutrients (below the photic zone) during strong and extended water stratification ${ }^{14,44}$.

Taxa from the above orders, which comprise bloom forming and toxic organisms, particularly species of the genus Microcystis (Chroococcales), D. lemmermannii (Nostocales), and $P$. rubescens (Oscillatoriales), increased in prevalence and geographic range across all lakes and over time (Fig. 5). Hierarchical clustering based on Euclidean distances revealed five clusters of taxa with different temporal patterns. Cluster I comprises five OTUs assigned to unicellular and non-bloom forming Synechococcus spp. (order Synechococcales) that were highly prevalent over all the studied time period. Cluster II contains taxa that were relatively rare (i.e. isolated in some lakes) until the 1990s when they became common in most lakes investigated Cluster II includes genera from Chroococcales (such as Microcystis) and Oscillatoriales (such as OTU \#344, 100\% similarity to P. rubescens previously isolated from Lake Zurich ${ }^{45}$ ). Cluster III, which contains about $43 \%$ of all OTUs identified in this study, is characterized by rare OTUs that were never highly prevalent across the study lakes. Some of these taxa were detected in a few lakes prior to the 1970s, and were not found in recent decades. Cluster IV is a group of taxa with relatively low prevalence throughout the twentieth century, but that are more common during the eutrophication peak. Finally, cluster V contains OTUs that mostly increased in prevalence after the period of maximal eutrophication between 
1950 and 1974, and that remained common thereafter. This cluster was characterized mostly by the presence of Chroococcales, Nostocales, and Oscillatoriales, including the genera Microcystis and the known invasive Dolichospermum (OTU \#614; 99\% similarity to D. lemmermannii LN871456) previously isolated from a southern peri-Alpine lake ${ }^{21}$. Overall, these results revealed long-term changes in prevalence of cyanobacterial taxa that were unknown to date across the region, and broadened our knowledge about dynamics of colonyforming cyanobacterial populations over recent decades ${ }^{20,21,46}$.

Earlier studies have reported the increasing occurrence of blooms of P. rubescens in recently re-oligotrophied lakes around the European Alps ${ }^{22}$. The competitive advantage of this cyanobacterium is thought to rest in its adaptation to low light conditions, and its ability to migrate vertically over the water column to harvest nutrients ${ }^{47}$. The invasion by $D$. lemmermannii, in several deep southern subalpine lakes was also recently reported ${ }^{20,21}$. In our study, we found two Dolichospermum spp. in the sediments of several northern peri-Alpine lakes in the 1800s and during the twentieth century (Fig. 5). In the southern lakes, however, D. spp. were only detected after the 1980s. Interestingly, these OTUs were found in sediments of all lakes, except in the oligotrophic Lake Annecy, suggesting that $D$. spp. are able to colonize a wide range of lakes where $\mathrm{N}$ and $\mathrm{P}$ are not limiting.

The interaction between climate warming and nutrient fluctuations likely played an important role in our study system. It appears to have favoured taxa able to thrive in environments with a more stable water column and where limiting nutrients were on a declining trend (after they had been enriched). For instance, colony-forming and buoyancyregulating species are favoured under such conditions ${ }^{15}$. Evidence in the literature supports the hypothesis that reduction in spatial environmental heterogeneity filters species traits and determines homogenization in the composition of natural communities across sites ${ }^{8,9}$. Coloniality, by increasing the species realized size, is also a grazing-defence trait ${ }^{48}$. We 
cannot exclude that top-down control from changing zooplankton communities might have played a role in our detected trends in cyanobacterial community composition. Recent experimental evidence suggests that grazers (i.e. Daphnia) can significantly affect the local and regional diversity and community composition of phytoplankton ${ }^{49}$. We have, however, no direct evidence from our data to test this hypothesis.

Our results reveal previously unreported patterns of taxa richness and community composition in cyanobacterial assemblages over spatial and temporal scales that are relevant to both lake ecology and environmental policy. We show prime evidence based on sedDNA that homogenization of natural communities has occurred in lake cyanobacterial assemblages during decades of climate change and eutrophication, and this process coincided with the spread of bloom forming and toxic cyanobacteria in the European peri-Alpine region ${ }^{21,22,36,46}$.

Our findings are relevant for a broad range of ecosystems under human-induced environmental pressure, as patterns of biotic homogenization similar to the ones reported here have been shown in marine fish communities, microbial decomposers, plants, and animals in grassland communities, with implications for local ecosystem services ${ }^{8,50}$. The results presented here are spatial- and temporal-scale dependent, and more knowledge is necessary about the state and history of cyanobacterial diversity and community composition on a European or continental scale. Loss of spatial beta diversity alongside regional changes in climate and nutrient loading signals a general problem in freshwater ecosystems that might not be reversible by applying traditional lake management schemes focused solely on phosphorus reduction. 


\section{Methods}

245

246

247

\section{Long-term physico-chemical characteristics of the lakes and environmental change.}

Seven lakes north, and three lakes south of the European Alps were cored between 2009 and 2014 (see the map in Supplementary Fig. 1). The lakes were selected on the basis of their geographical location, their eutrophication history, and because they cover a wide gradient of trophic levels and morphological characteristics (Supplementary Table 1). Water samples from these lakes have been collected and analysed as part of multiple sampling programmes by various governmental and institutional instances over the last two to six decades (See Supplementary Table 2 for details about sampling and source of monitoring data). Total phosphorus (TP) and nitrate $\left(\mathrm{NO}_{3}-\mathrm{N}\right)$ concentrations were generally determined on a monthly basis. From these time series, we averaged $\mathrm{TP}$ and $\mathrm{NO}_{3}-\mathrm{N}$ integrated over the 20 uppermost meters, or over whole water when the depth-resolved data was not available (Lake Pusiano). We used publicly available homogenized monthly air temperature data ${ }^{51}$ recorded at the three following meteorological stations (see map in Supplementary Fig. 1): Zurich/Fluntern (N; Alpine north side - eastern Plateau), Lugano (S; Alpine south side), and Geneva (NW; Alpine north side - western Plateau) to show the increase in air temperature between the years 1860 and 2015.

Water stability index. We used the Schmidt Stability Index (SSI; as defined by ${ }^{52}$ ) to calculate the strength of the water column thermal stratification in all the lakes, with the exception of Lake Pusiano where no depth-resolved temperature profiles were available. The maximal annual index values were obtained for each lake in years during which a minimum of three profiles had been collected in summer (between July and September; $n=312$ ). To account for possible biases related to an uneven number of temperature profiles sampled per year, the depth-resolved water stability profiles were bootstrapped 1,000 times by choosing 3 random points during the summer period, and were compared to hourly-resolved one- 
269

270

271

272

273

274

275

dimensional hydrodynamic model recently published on Lake Geneva ${ }^{53}$. The estimated error in the maximal SSI calculation was around $8 \%$ over a period of 30 years.

Sediment core sampling and dating. Two types of gravity corer (UWITEC-63 or Eawag63/S corer) were used to collect sediment cores of approximately $1 \mathrm{~m}$ in length and $63 \mathrm{~mm}$ in diameter in 10 peri-Alpine lakes between 2009 and 2015. The cores from Greifensee, Hallwilersee, Baldeggersee, Lake Zurich, Lake Constance, Lake Lugano, Lake Maggiore and Lake Pusiano were transported to Eawag facilities in Dübendorf where they were stored in upright position in the dark at $4^{\circ} \mathrm{C}$ until analysis. The cores from Lake Geneva and Lake Annecy were preserved and processed similarly at INRA (Thonon-Les-Bains, France).

The cores collected in Greifensee and Lake Zurich had been previously dated based on varve counting, in addition to radiometric methods for the Greifensee core $\left({ }^{210} \mathrm{~Pb},{ }^{226} \mathrm{Ra}\right.$, ${ }^{137} \mathrm{Cs}$ ) ${ }^{28}$. The sediments in all other cores were dated based on both varve counting (when applicable) and radiometric methods (Supplementary Fig. 4). A core from each lake was opened longitudinally, photographed, and described. A half core from each lake was subsampled at 1-cm intervals for radionuclide measurements on a high-purity germanium (HPGe) well detector (gamma spectrometer, Canberra Industries Inc.) at the Eawag (Switzerland) for lakes Hallwilersee, Baldeggersee, Constance, Lugano, Maggiore, and Pusiano) and at the Modane underground laboratory (LSM environmental radioactivity facility, France) for lakes Annecy and Geneva.

Molecular analysis. The sediment samples dedicated to sedimentary DNA (sedDNA) analysis were collected either from a half of the reference core, or from a second half-core that was correlated to the reference core based on lithological tie points and lamina counting performed on the reference and working cores. All sediment cores were opened and processed in a room where no genetic or molecular work had been done before, following procedures to 
293

294

295

296

297

298

299

300

301

302

303

304

305

306

307

308

309

310

311

312

313

314

315

316

317

reduce contamination with foreign DNA, as detailed in ${ }^{28}$. The sediment samples were

collected in sterile tubes and transferred to a clean laboratory facility, where no PCR work has been done before and where strict clean laboratory procedures are followed. Briefly, disposable gloves, shoe covers, and a head net were worn, and a clean laboratory coat was used each time. The DNA extraction and PCR preparation steps were carried out inside a laminar flow hood cleaned with bleach and sterilized under UV light for at least 20 minutes prior to use. The PCRs and post-PCR steps were carried out in a regular molecular genetic laboratory, and PCR products were never in contact with the sediment or the DNA samples. DNA was extracted from approximately $1 \mathrm{~g}$ of sediments using the PowerSoil DNA Isolation kit (MoBio Laboratories, Inc., CA, USA) for all lakes except Geneva and Annecy, for which the UltraClean Soil DNA Isolation Kit from the same company was used, according to the manufacturer's instructions. DNA extractions were performed in batches of seven samples, with the addition of one extraction negative control each time. Each sediment layer was used for two independent extractions performed at different times, and the two extracts were subsequently combined to reduce heterogeneity.

The sequencing library preparation was done following the MetaFast protocol developed by Fasteris (Geneva, Switzerland) using cyanobacteria-specific primers ${ }^{54}$ that included a 1012 nt-long tag for identifying the samples and for creating size variation in the amplicon (Supplementary Table 3). PCR reactions in a final volume of $40 \mu \mathrm{L}$ contained $1 \times$ AmpliTaq Gold Buffer I (Thermofisher Scientific), $0.2 \mathrm{mM}$ of each dNTP, $0.5 \times \mathrm{MgCl}_{2}, 1.25 \mathrm{U}$ AmpliTaq Gold polymerase, $0.2 \mu \mathrm{g} / \mu \mathrm{L}$ BSA, and $0.2 \mu \mathrm{M}$ each primer (Microsynth, Balgach, Switzerland) and $3 \mu \mathrm{L}$ template sedDNA at a concentration of $4 \mathrm{ng} / \mu \mathrm{L}$ (slightly less in the 10 samples with a lower sedDNA concentration). The PCR program on the thermal cycler included a first denaturation step at $95^{\circ} \mathrm{C} 10 \mathrm{~min}, 35$ cycles of $95^{\circ} \mathrm{C}$ for $15 \mathrm{~s}, 60^{\circ} \mathrm{C}$ for $30 \mathrm{~s}$ and $72^{\circ} \mathrm{C}$ for $45 \mathrm{~s}$, followed by a last extension step at $72^{\circ} \mathrm{C} 5$ min. Each PCR plate contained 
between 30 to 96 samples (including negative controls at a ratio of 1 per 8-11 samples). PCR was replicated three times in independent PCR runs, and the products of each sample were pooled. These pooled PCR products were then purified using the Illustra GFX PCR DNA and gel band purification kit (GE Healthcare, Chicago, Illinois, USA) and eluted in $30 \mu \mathrm{L}$ of TE buffer (10 mM). Purified PCR products were finally quantified with a Qubit Fluorometer, and a total of 111 samples were pooled in equimolar concentration into one multiplex library. Negative PCR controls (i.e. PCR reactions not containing DNA template) were added to the sequencing run to control for contamination. The final library was sent to the Fasteris sequencing company (Geneva, Switzerland) for the adapter ligation and sequencing on a MiSeq Illumina platform.

Sequence data processing. For the quality control and processing of the sequencing data, we followed an in-house workflow developed at the Genomic Diversity Centre (GDC; ETH Zürich, adapted from ${ }^{28}$ ). A total of 10,609,311 quality-checked, primer-trimmed and cleaned sequences from 111 samples were clustered in 2,826 operational taxonomic units (OTUs) using the UPARSE workflow ${ }^{55}$ at a minimum sequence similarity of $97 \%$ and a read abundance threshold of 5. Four samples had fewer than 10,000 reads each, and were therefore removed from the dataset. Finally, we filtered out OTUs that were not assigned to cyanobacteria (confidence threshold of 0.89), and removed 13 more OTUs that were found in less than three samples over the whole dataset. This was done to reduce biases introduced by very rare taxa or possible sequencing errors. The seven negative controls that were included in the sequencing run each comprised less than $1 \%$ of the reads compared to the samples average, and were therefore removed. For the OTU richness estimation, the OTU counts were rarefied to account for differences in sequencing depth. In total, the filtered dataset comprised 143 OTUs assigned to photosynthetic cyanobacteria distributed across 108 samples. After the rarefaction step, 133 OTUs in 76 samples were left. 
The taxonomic assignment of the OTUs was based upon a GreenGenes database ${ }^{56}$ supplemented with few decoy sequences belonging to non-cyanobacterial prokaryotes (see ${ }^{28}$ ). Of the 143 photosynthetic cyanobacteria OTUs found in this study, 139 were assigned to order level, 125 were assigned to family level, 65 were assigned to genus level, and none were assigned a species name with high confidence (based on a confidence threshold of 0.89).

Phylogenetic diversity estimation. The reference sequences for each cyanobacterial OTU were aligned with PyNAST ${ }^{57}$ and used to infer a phylogeny based on maximum likelihood in FastTree ${ }^{58}$. All diversity analyses were performed with the software R v3.3.2 ${ }^{59}$. The phyloseq package in Bioconductor ${ }^{60}$ was used to import, visualize, and subset sequence data, as well as for estimating richness and community similarity, which we respectively defined as the number of OTUs in a lake at a given point in time, and the compositional dissimilarity between sites. Community dissimilarity was estimated using both taxonomic-based (Jaccard) ${ }^{61}$ and phylogenetic-based (Unifrac) distances ${ }^{62}$. The patterns were comparable between the Jaccard and Unifrac indices; therefore we present and discuss only the analyses based on phylogenetic distances. We estimated OTU richness in the meta-community formed by all lakes at each given point in time using randomization in the function 'specaccum' in the vegan ${ }^{63}$ package for $\mathrm{R}$. The rarefied OTU counts were used to estimate richness and community dissimilarity.

Compositional turnover. We compared the phylogenetic dissimilarity among communities of lakes using the function 'adonis' in the vegan package by permutational multivariate analysis of variance using distance matrices (PERMANOVA). The samples were split in different time periods to cover the timespan of the study. The number of samples prior to the 1940s was insufficient for calculating pairwise dissimilarity across communities, and therefore these samples were excluded from the analysis. To understand changes in cyanobacterial community composition across sites, we studied the prevalence and 
distribution of shared and specific OTUs across the 10 lakes over time. We calculated the proportion of lakes where each OTU was found at each given time period (prevalence). The colour-coded image map of taxa prevalence was produced using CIMminer ${ }^{64}$ and taxa were clustered for pattern detection by calculating Euclidean distances based on prevalence and the dendrogram constructed by average linkage method. Rare OTUs were defined as the OTUs found in less than $25 \%$ of the lakes at a given time period, and the common OTUs were defined as the ones present in at least $75 \%$ of the lakes at a given time period.

Statistical models. Our objective was to compare and quantify the strength of the relationship between cyanobacteria and environmental drivers (strength of water thermal stratification, TP, and $\mathrm{NO}_{3}-\mathrm{N}$ ) over the last century in the 10 peri-Alpine lakes. The annual average values of $\mathrm{NO}_{3}-\mathrm{N}$ and $\mathrm{TP}$ of the year before, the year, and the year after the approximate year corresponding to a sedDNA sample was calculated for each observation (i.e. for a sample dated to year 1990, the mean nutrient values of years 1989, 1990, and 1991 were averaged and used in the model). This averaging over a 3-year period was done to account for uncertainties related to the sediments dating. The abiotic variables were weakly crosscorrelated $(\mathrm{r}<0.55)$. OTU richness was used as response variables in individual models, and a lake random effect was evaluated. We applied a natural logarithm transformation to the response variable, and verified that the residuals were normally distributed. We used linear mixed-effect models (LMMs) from the 'Ime4' package for R based on the 30 observations for which OTU richness, depth-resolved water temperature, $\mathrm{TP}$, and $\mathrm{NO}_{3}-\mathrm{N}$ data were available (Lake Annecy and Lake Pusiano were therefore excluded from the model). The best model was selected based on the comparison of the nested models using parametric bootstrap methods in the pbkrtest package for R.

For calculating community similarities, and for reporting the richness and prevalence of OTUs over time across all sites, the sedDNA samples were grouped by time periods of either 
ten or twenty-five years, depending on data availability. The lakes chemical data were pooled in a similar way (twenty-five-year periods) to reflect temporal changes in the overall nutrient concentrations across lakes (Fig. 1e-f).

\section{Data availability statement}

The Illumina sequence data that support the findings of this study have been deposited in the European Nucleotide Archive (ENA) with the project number PRJEB21329.

\section{Acknowledgements}

High-throughput sequencing data was produced at Fasteris (Geneva). We thank J-C. Walser (GDC; ETH Zürich) for bioinformatics support, and B. Müller for helping with lake chemical data acquisition. We thank M. Thali, A. Lück, A. Zwyssig, C. Chardon, A. Lami, S. Gerli, H. Penson, and C. Ouellet-Plamondon for technical assistance, as well as M. Lavrieux for help with the sediment dating. We are grateful to I. Gregory Eaves, H. Hartikainen, R. Ptacnik, K. Räsänen, C. Tellenbach, and M.K. Thomas for intellectual feedback and fruitful discussions. Coring, dating and DNA extractions for lakes Annecy and Geneva were performed in the context of the "REPLAY" program funded by EC2CO INSU, and the Iper Retro program funded by ANR- VULNS-005 (France). Physical-chemical data of Greifensee was produced by AWEL (Canton Zurich); Wasserversorgung Zürich (WVZ) for Lake Zurich; Lake Constance Water Supply for Lake Constance; Abteilung für Umwelt (AfU) Kanton Aargau (A. Stöckli) for Hallwilersee; Eawag/Kanton Luzern for Baldeggersee; F. Lepori, the Swiss Federal Office for the Environment (FOEN) and CIPAIS for Lake Lugano; M. Manca (CNR Institute of Ecosystem Study, Italy) for Lake Maggiore; the Observatory on Alpine Lakes (SOERE OLA), CIPEL, SILA, and OLA-IS developed by Eco-Informatics ORE INRA for lakes Annecy and Geneva; and G. Tartari (IRSA-CNR Brugherio, Italy) for lake Pusiano. This work was supported by the Swiss Enlargement Contribution, project IZERZ0 - 142165, "CyanoArchive” to Piet Spaak, in the framework of the Romanian-Swiss Research Programme. 


\section{Author contributions}

423 M-E.M., P.S. and F.P. designed the study. I.D. and N.D. contributed materials/analysis

424 tools/samples. M-E.M. and I.D. collected data, and all the analyses were carried out by M-

425 E.M. and D.B.. M-E.M. and F.P. wrote the manuscript, which was revised and edited by all

426 authors.

427

428 Declaration of financial competing interests

429 The authors declare no financial competing interests.

430

431 


\section{References}

432 1. Vitousek, P. M., Mooney, H. A., Lubchenco, J. \& Melillo, J. M. Human Domination of

433

434

435

436

437

438

439

440

441

442

443

444

445

446

447

448

449

450

451

452

453

454

455

456

457

458

459

460

461

462

463

464 465 Earth’ s Ecosystems. Science. 277, 494-499 (1997).

2. Newbold, T. et al. Global effects of land use on local terrestrial biodiversity. Nature 520, 45-50 (2015).

3. Vellend, M. Conceptual Synthesis in Community Ecology. Q. Rev. Biol. 85, 183-206 (2010).

4. McGill, B. J., Dornelas, M., Gotelli, N. J. \& Magurran, A. E. Fifteen forms of biodiversity trend in the anthropocene. Trends Ecol. Evol. 30, 104 (2015).

5. González-Orozco, C. E. et al. Phylogenetic approaches reveal biodiversity threats under climate change. Nat. Clim. Chang. 6, 1110-1114 (2016).

6. Vellend, M. et al. Estimates of local biodiversity change over time stand up to scrutiny. bioRxiv 0, 62133 (2016).

7. Dornelas, M. et al. Assemblage Time Series Reveal Biodiversity Change but Not Systematic Loss. Science. 344, 296-299 (2014).

8. Magurran, A. E., Dornelas, M., Moyes, F., Gotelli, N. J. \& McGill, B. Rapid biotic homogenization of marine fish assemblages. Nat. Commun. 6, 8405 (2015).

9. Gámez-Virués, S. et al. Landscape simplification filters species traits and drives biotic homogenization. Nat. Commun. 6, 8568 (2015).

10. Cardinale, B. J. et al. Corrigendum: Biodiversity loss and its impact on humanity. Nature 486, 59-67 (2012).

11. Adrian, R., O’Reilly, C. M., Zagarese, H., Baines, S. B. \& Dag, O. Lakes as sentinels of climate change. Limnol. Oceanogr. 54, 2283-2297 (2009).

12. Sukenik, A., Quesada, A. \& Salmaso, N. Global expansion of toxic and non-toxic cyanobacteria: effect on ecosystem functioning. Biodivers. Conserv. 24, 889-908 (2015).

13. Paerl, H. W. \& Huisman, J. Climate - Blooms like it hot. Science. 320, 57-58 (2008).

14. Carey, C. C., Ibelings, B. W., Hoffmann, E. P., Hamilton, D. P. \& Brookes, J. D. Ecophysiological adaptations that favour freshwater cyanobacteria in a changing climate. Water Res. 46, 1394-1407 (2012).

15. Rigosi, A., Carey, C. C., Ibelings, B. W. \& Brookes, J. D. The interaction between climate warming and eutrophication to promote cyanobacteria is dependent on trophic state and varies among taxa. Limnol. Ocean. 59, 99-114 (2014).

16. Vonlanthen, P. et al. Eutrophication causes speciation reversal in whitefish adaptive radiations. Nature 482, 357-362 (2012). 
17. Downing, J. A. J., Watson, S. S. B. \& McCauley, E. Predicting Cyanobacteria dominance in lakes. Can. J. Fish. Aquat. Sci. 58, 1905-1908 (2001).

18. Taranu, Z. E. et al. Acceleration of cyanobacterial dominance in north temperatesubarctic lakes during the Anthropocene. Ecol. Lett. 18, 375-384 (2015).

19. Sinha, R. et al. Increased incidence of Cylindrospermopsis raciborskii in temperate zones - Is climate change responsible? Water Res. 46, 1408-1419 (2012).

20. Salmaso, N. et al. Historical colonization patterns of Dolichospermum lemmermannii (Cyanobacteria) in a deep lake south of the Alps. Adv. Oceanogr. Limnol. 6, 1-4 (2015).

21. Salmaso, N., Capelli, C., Shams, S. \& Cerasino, L. Expansion of bloom-forming Dolichospermum lemmermannii (Nostocales, Cyanobacteria) to the deep lakes south of the Alps: Colonization patterns, driving forces and implications for water use. Harmful Algae 50, 76-87 (2015).

22. Ernst, B., Hoeger, S. J., O’Brien, E. \& Dietrich, D. R. Abundance and toxicity of Planktothrix rubescens in the pre-alpine Lake Ammersee, Germany. Harmful Algae 8, 329-342 (2009).

23. Otten, T. G., Xu, H., Qin, B., Zhu, G. \& Paerl, H. W. Spatiotemporal patterns and ecophysiology of toxigenic microcystis blooms in Lake Taihu, China: implications for water quality management. Environ. Sci. Technol. 46, 3480-8 (2012).

24. Glibert, P. M., Harrison, J., Heil, C. \& Seitzinger, S. Escalating Worldwide use of Urea - A Global Change Contributing to Coastal Eutrophication. Biogeochemistry 77, 441463 (2006).

25. Domaizon, I., Winegardner, A., Capo, E., Gauthier, J. \& Gregory-Eaves, I. DNA-based methods in paleolimnology: new opportunities for investigating long-term dynamics of lacustrine biodiversity. J. Paleolimnol. (2017). doi:10.1007/s10933-017-9958-y

26. Domaizon, I. et al. DNA from lake sediments reveals the long-term dynamics and diversity of Synechococcus assemblages. Biogeosciences Discuss. 10, 2515-2564 (2013).

27. Savichtcheva, O. et al. Effects of nutrients and warming on Planktothrix dynamics and diversity: A palaeolimnological view based on sedimentary DNA and RNA. Freshw. Biol. 60, 31-49 (2015).

28. Monchamp, M.-E., Walser, J.-C., Pomati, F. \& Spaak, P. Sedimentary DNA reveals cyanobacterial community diversity over 200 years in two perialpine lakes. Appl. Environ. Microbiol. 82, 6472-6482 (2016).

29. Vellend, M. et al. Global meta-analysis reveals no net change in local-scale plant biodiversity over time. Proc. Natl. Acad. Sci. U. S. A. 110, 19456-9 (2013).

30. Hou, W. et al. Identification of photosynthetic plankton communities using 
sedimentary ancient DNA and their response to late-Holocene climate change on the Tibetan Plateau. Sci. Rep. 4, 6648 (2014).

31. Coolen, M. J. L. et al. Ancient DNA derived from alkenone-biosynthesizing haptophytes and other algae in Holocene sediments from the Black Sea. Paleoceanography 21, 1-17 (2006).

32. Boere, A. C., Sinninghe Damsté, J. S., Rijpstra, W. I. C., Volkman, J. K. \& Coolen, M. J. L. Source-specific variability in post-depositional DNA preservation with potential implications for DNA based paleoecological records. Org. Geochem. 42, 1216-1225 (2011).

33. Züllig, H. Untersuchungen über die Stratigraphie von Carotinoiden im geschichteten Sediment von 10 Schweizer Seen zur Erkundung früherer Phytoplankton-Entfaltungen. Schweizerische Zeitschrift für Hydrol. 44, 1-98 (1982).

34. Liechti, P. L'Etat des Lacs en Suisse. Cahier de l'Environnement 237, (1994).

35. Pomati, F., Matthews, B., Jokela, J., Schildknecht, A. \& Ibelings, B. W. Effects of reoligotrophication and climate warming on plankton richness and community stability in a deep mesotrophic lake. Oikos 121, 1317-1327 (2012).

36. Posch, T., Köster, O., Salcher, M. M. \& Pernthaler, J. Harmful filamentous cyanobacteria favoured by reduced water turnover with lake warming. Nat. Clim. Chang. 2, 809-813 (2012).

37. Livingstone, D. M. Thermal Structure of a Large Temperate Central European Lake. Clim. Change 57, 205-225 (2003).

38. Matthews, B. \& Pomati, F. Reversal in the relationship between species richness and turnover in a phytoplankton community. Ecology 93, 2435-2447 (2012).

39. Sukenik, A. et al. Invasion of Nostocales (cyanobacteria) to subtropical and temperate freshwater lakes - physiological, regional, and global driving forces. Front. Microbiol. 3, 1-9 (2012).

40. Cirés, S., Wörmer, L., Wiedner, C. \& Quesada, A. Temperature-Dependent Dispersal Strategies of Aphanizomenon ovalisporum (Nostocales, Cyanobacteria): Implications for the Annual Life Cycle. Microb. Ecol. 65, 12-21 (2013).

41. Gallina, N., Salmaso, N., Morabito, G. \& Beniston, M. Phytoplankton configuration in six deep lakes in the peri-Alpine region: are the key drivers related to eutrophication and climate? Aquat. Ecol. 47, 177-193 (2013).

42. Salmaso, N. Long-term phytoplankton community changes in a deep subalpine lake: responses to nutrient availability and climatic fluctuations. Freshw. Biol. 55, 825-846 (2010).

43. Anneville, O., Souissi, S., Gammeter, S. \& Straile, D. Seasonal and inter-annual scales of variability in phytoplankton assemblages: comparison of phytoplankton dynamics in 
three peri-alpine lakes over a period of 28 years. Freshw. Biol. 49, 98-115 (2004).

541

542

543

544

545

546

547

548

549

550

551

552

553

554

555

556

557

558

559

560

561

562

563

564

565

566

567

568

569

570

571

572

573

574

575

44. Reynolds, C., Oliver, R. \& Walsby, A. Cyanobacterial dominance: the role of buoyancy regulation in dynamic lake environments. New Zeal. J. Mar. Freshw. Res. 21, (1987).

45. Beard, S. J., Handley, B. A., Hayes, P. K. \& Walsby, A. E. The diversity of gas vesicle genes in Planktothrix rubescens from Lake Zurich. Microbiology 145, 2757-2768 (1999).

46. Jacquet, S. et al. The proliferation of the toxic cyanobacterium Planktothrix rubescens following restoration of the largest natural French lake (Lac du Bourget). Harmful Algae 4, 651-672 (2005).

47. Walsby, A. E. Stratification by cyanobacteria in lakes: A dynamic buoyancy model indicates size limitations met by Planktothrix rubescens filaments. New Phytol. 168, 365-376 (2005).

48. Litchman, E. \& Klausmeier, C. a. Trait-Based Community Ecology of Phytoplankton. Annu. Rev. Ecol. Evol. Syst. 39, 615-639 (2008).

49. Birtel, J. \& Matthews, B. Grazers structure the bacterial and algal diversity of aquatic metacommunities. Ecology 97, 3472-3484 (2016).

50. Gossner, M. M. et al. Land-use intensification causes multitrophic homogenization of grassland communities. Nature 540, (2016).

51. Begert, M., Schlegel, T. \& Kirchhofer, W. Homogeneous temperature and precipitation series of Switzerland from 1864 to 2000. Int. J. Climatol. 25, 65-80 (2005).

52. Schmidt, W. Über die Temperatur- und Stabilitätsverhältnisse von Seen. Geogr. Ann. (1928).

53. Schwefel, R., Gaudard, A., Wüest, A. \& Bouffard, D. Effects of climate change on deepwater oxygen and winter mixing in a deep lake (Lake Geneva): Comparing observational findings andmodeling. Water Resour. Res. 8811-8826 (2016). doi:10.1002/2016WR019194

54. Nübel, U., Garcia-pichel, F., Muyzer, G., Nu, U. \& Muyzer, G. PCR primers to amplify 16S rRNA genes from cyanobacteria. Appl. Environ. Microbiol. 63, 3327-3332 (1997).

55. Edgar, R. C. UPARSE: highly accurate OTU sequences from microbial amplicon reads. Nat. Methods 10, 996-8 (2013).

56. McDonald, D. et al. An improved Greengenes taxonomy with explicit ranks for ecological and evolutionary analyses of bacteria and archaea. ISME J. 6, 610-618 (2012).

57. Caporaso, J. G. et al. PyNAST: A flexible tool for aligning sequences to a template alignment. Bioinformatics 26, 266-267 (2010). 
576 58. Price, M. N., Dehal, P. S. \& Arkin, A. P. FastTree 2 - Approximately maximum-

$577 \quad$ likelihood trees for large alignments. PLoS One 5, e9490 (2010).

578 59. R Core Team. R: A language and environment for statistical computing. R Foundation $579 \quad$ for Statistical Computing (2013).

580 60. McMurdie, P. J. \& Holmes, S. Phyloseq: An R Package for Reproducible Interactive $581 \quad$ Analysis and Graphics of Microbiome Census Data. PLoS One 8, (2013).

582 61. Faith, D. P., Minchin, P. R. \& Belbin, L. Compsitional dissimilarity as a robust 583 measure of ecogical distance. Vegetatio 69, 57-68 (1987).

584 62. Lozupone, C. \& Knight, R. UniFrac: a new phylogenetic method for comparing 585 microbial communities. Appl. Environ. Microbiol. 71, 8228-35 (2005).

586 63. Oksanen, J. et al. vegan: Community Ecology Package. R package version 2.0-10.

587 http://CRAN.R-project.org/package=vegan (2013).

588 64. Weinstein, J. N. et al. An information-intensive approach to the molecular 589 pharmacology of cancer. Science. 275, 343-349 (1997).

590 
Figure 1. History of environmental conditions in the 10 peri-Alpine lakes. (a) Normalized

Schmidt Stability Index (SSI) values plotted against time. The dashed line shows the average

SSI value over all lakes and time points, and the black line shows the significant linear fit. (b)

Annual average total phosphorus concentrations in the water column (full lines), and log scale $\left(\mathrm{NO}_{3}-\mathrm{N},[\mathrm{mg} / \mathrm{L}]\right)$. (d) Pairwise difference between mean annual air temperatures at three meteorological stations (N; Alpine north side - eastern Plateau, NW; Alpine north side -

601

602

603

604

605

606

607

608

609

610

611

612

613

614

western Plateau, and S; Alpine south side). The significant linear fit in each time series

(NW-S: adj. $\mathrm{R}^{2}=0.156, p=8.08 \times 10^{-12} ; \mathrm{N}-\mathrm{S}:$ adj. $\mathrm{R}^{2}=0.0949, p=1.10 \times 10^{-10}$ ) is indicated

with a full line. (e) Violin plots showing the probability density, median, and interquartile

range of TP and (f) $\mathrm{NO}_{3}-\mathrm{N}$ concentrations during the periods of eutrophication (1950-1974;

1975-1999) and post-eutrophication (2000-2015).

\section{Figure 2. Changes in cyanobacterial OTU richness and phylogenetic structure. (a)}

Temporal plot of rarefied OTU richness. Coloured lines show the lake-specific significant (full lines) or non-significant (dashed lines) relationships and the black line shows the overall fit for all lakes combined. (b) Species accumulation curves showing the average regional OTU richness estimated for a given number of lakes sampled at different periods. The 95\% confidence intervals for each curve are shown for reference in Supplementary Fig. 3. (c) Lntransformed OTU richness relative to normalized annual maximal SSI values and lntransformed mean annual TP concentrations across all lakes over the last century. (d) Violin plots showing the probability density, median, and interquartile range of pairwise unweighted 
615 Unifrac similarities estimated across lake communities at each decade. The horizontal line at 6160.43 represents the mean value of pairwise similarity across all samples.

617 Figure 3. Proportion of rare and common OTUs across all lakes. Samples were grouped 618 either by 10 or 25 years in order to have the highest possible number of lakes at each period 619 without replication of lakes within each group. A conceptual model depicting the intensity of 620 change in temperature (increased warming, red) and phosphorus concentrations 621 (eutrophication, darker green) in lakes is shown above the graphs for interpretation of 622 patterns.

Figure 4. OTU richness change within cyanobacterial orders. The solid black lines

624 indicate significant fits of the generalized additive model (GAM) at a $p<0.05$ level, and the 625 shaded areas around the curves show the confidence intervals at 95\%.

626 Figure 5. Prevalence of OTUs in all lakes between the 1900s and 2015. The gradient of red

627 illustrates the proportion of lakes where each taxon was found at each given period

628 (prevalence), while the absence of an OTU at a given period is depicted by a white box. 


\section{$\mathbf{a}$}

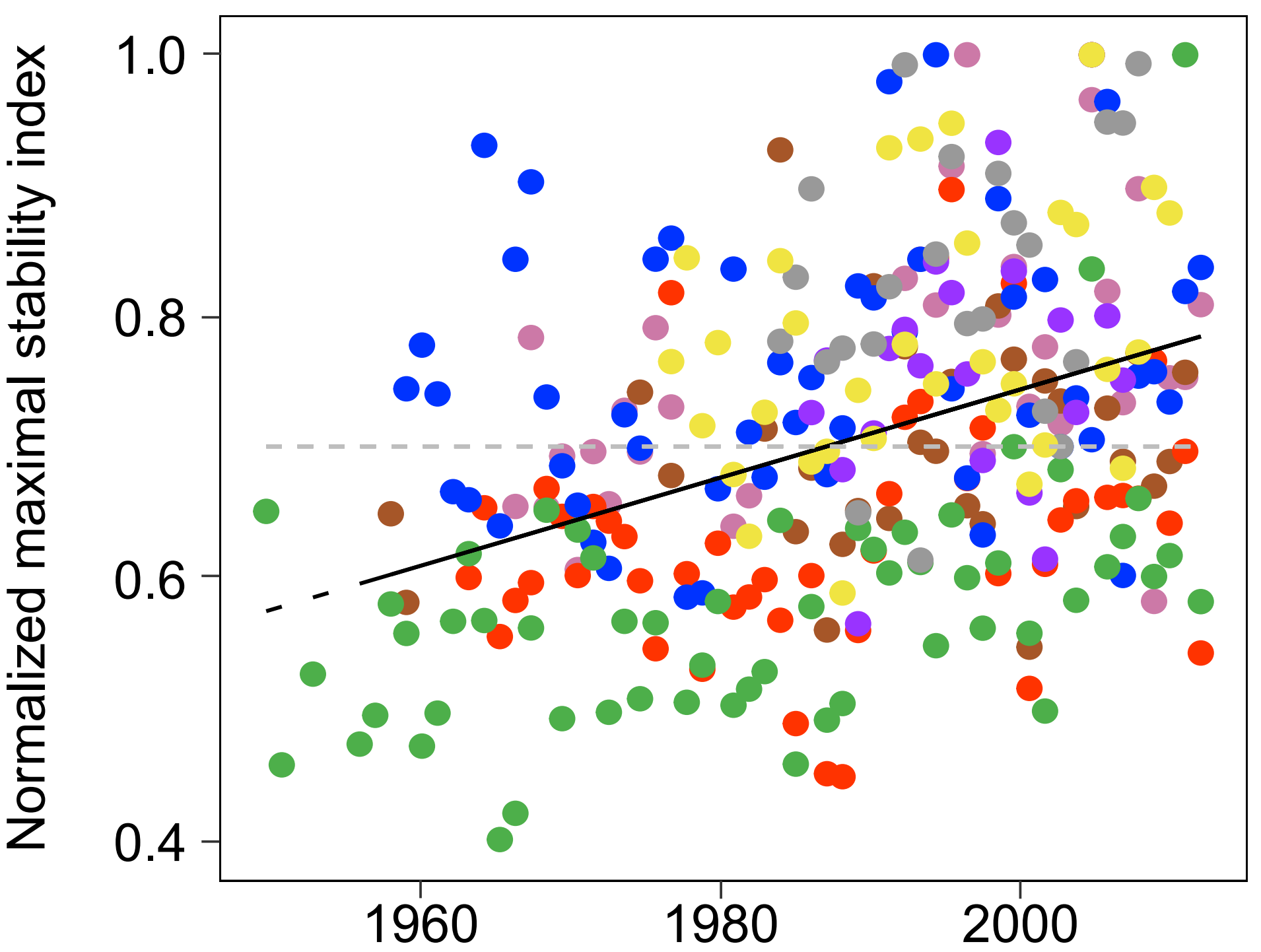


b

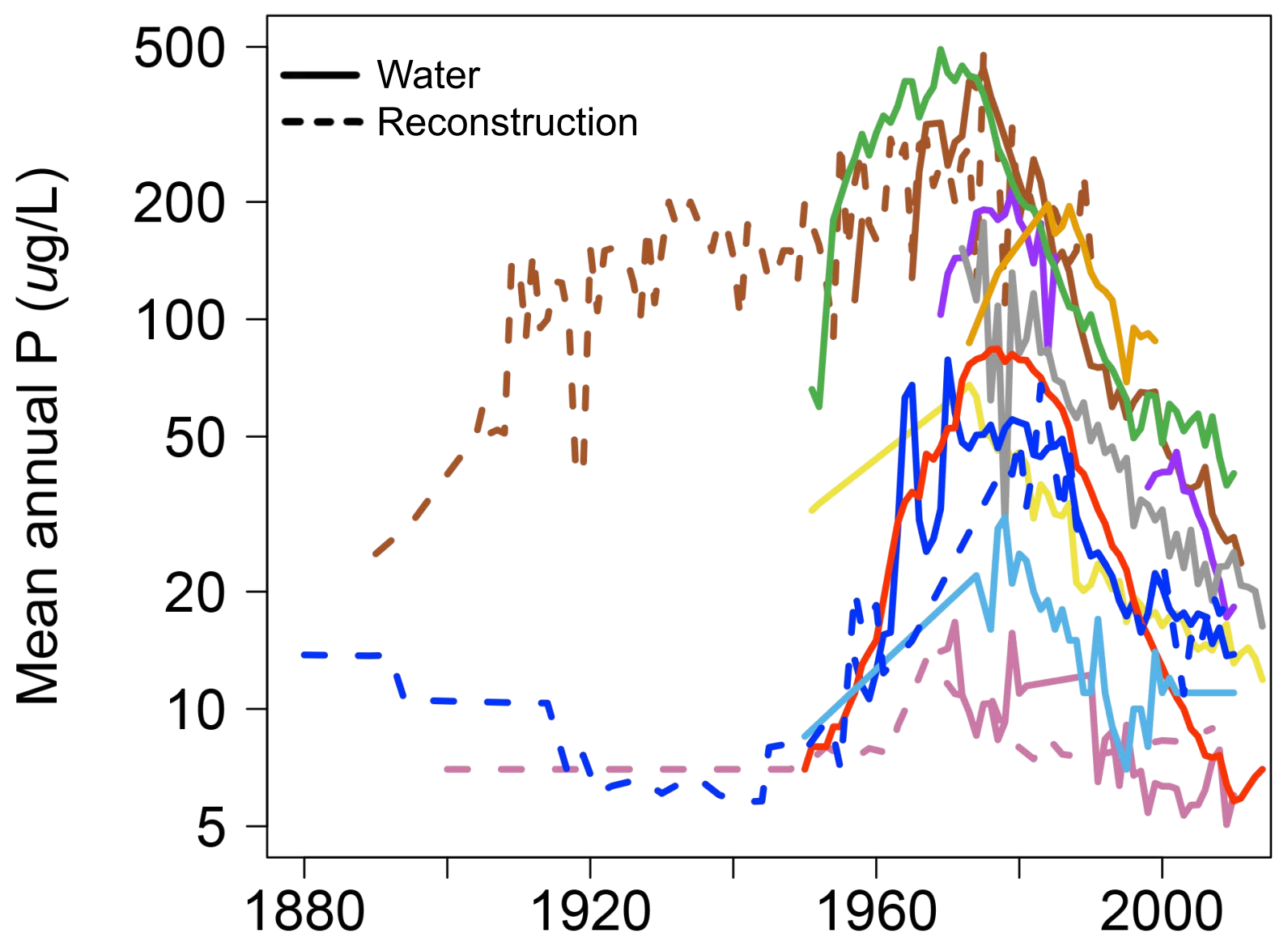




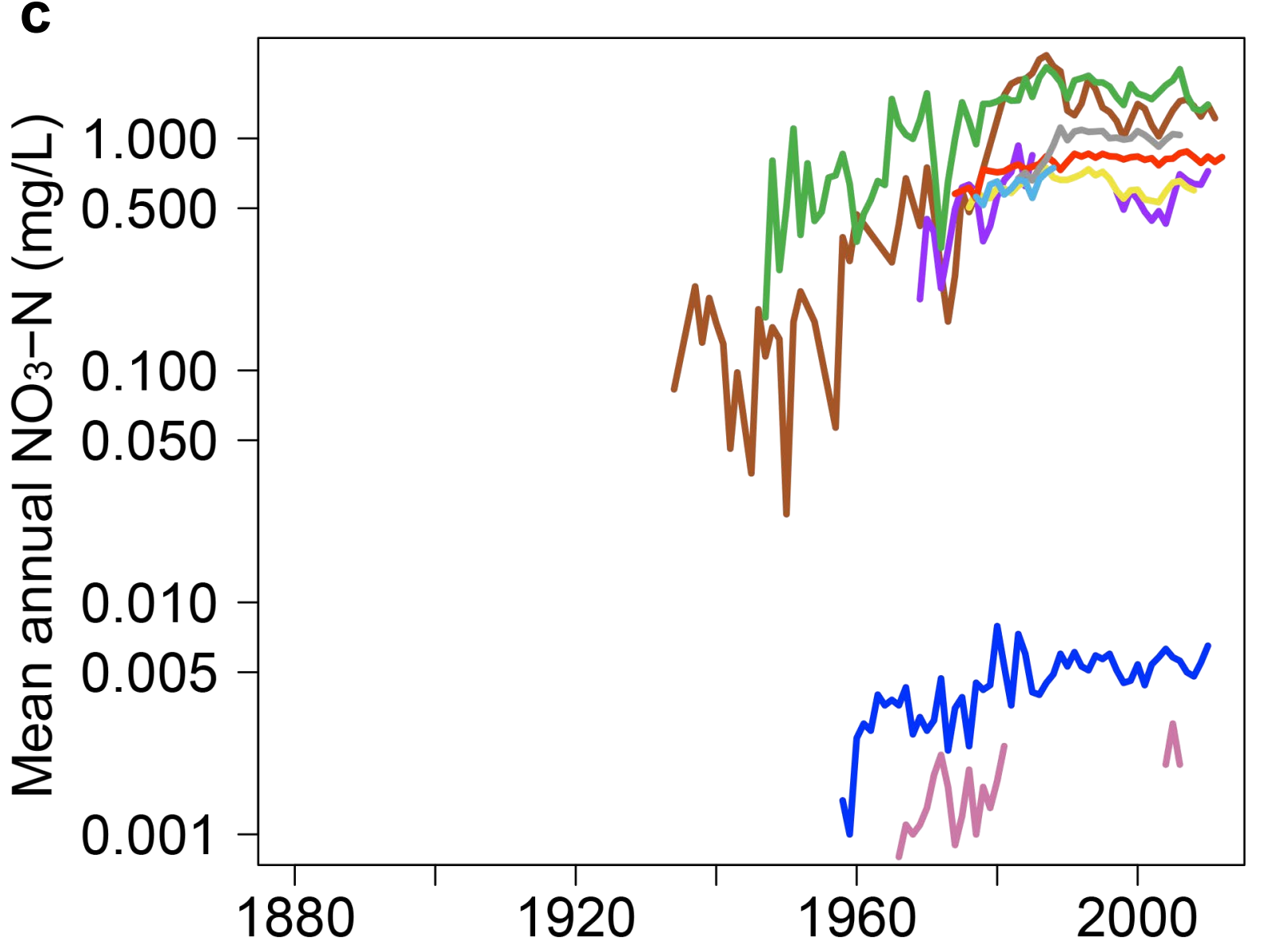




\section{Lake}

Lugano

Pusiano

Maggiore

Constance

Greifensee

Zurich

Hallwilersee

Baldeggersee

Annecy

Geneva 
d

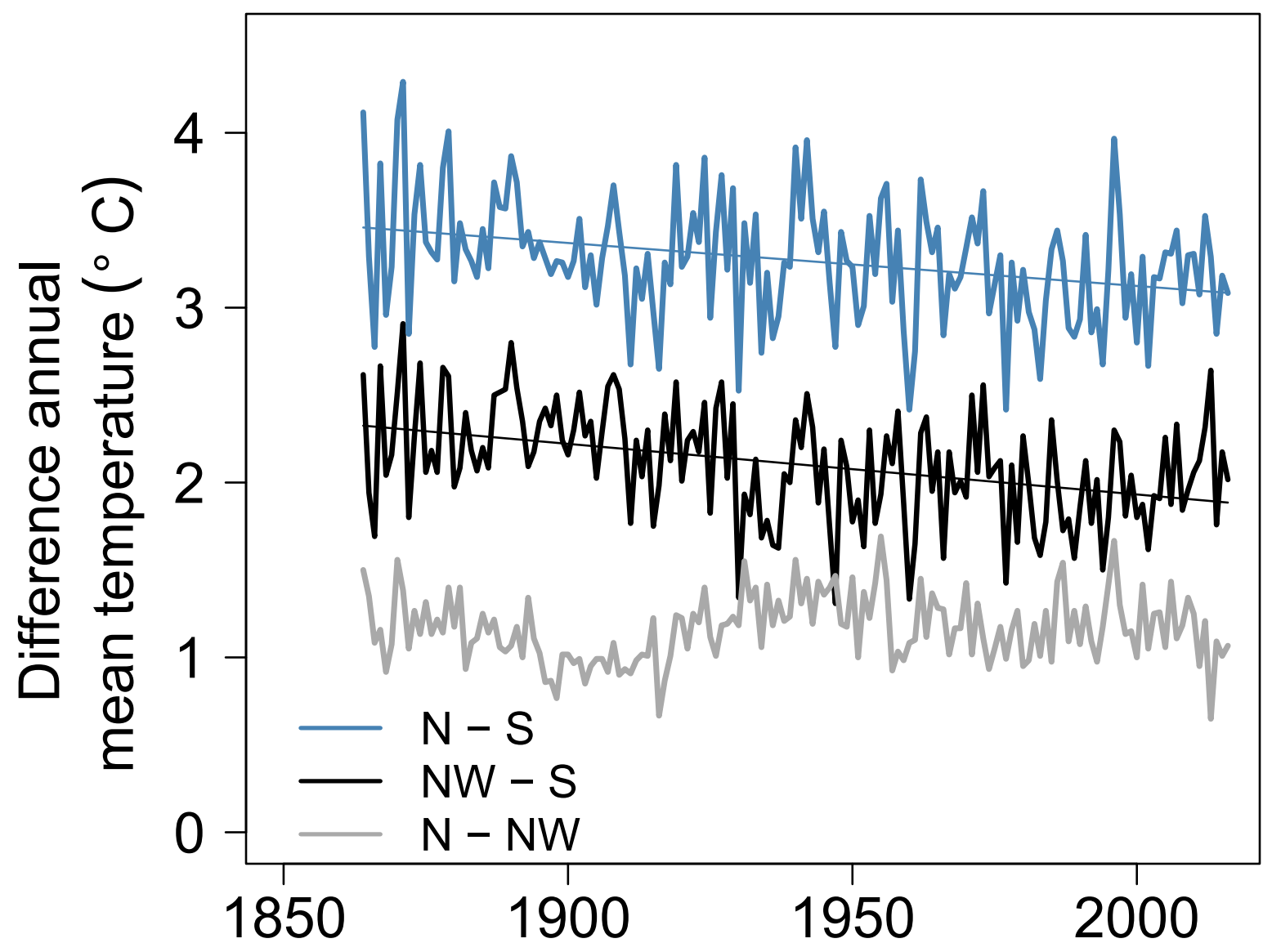


e

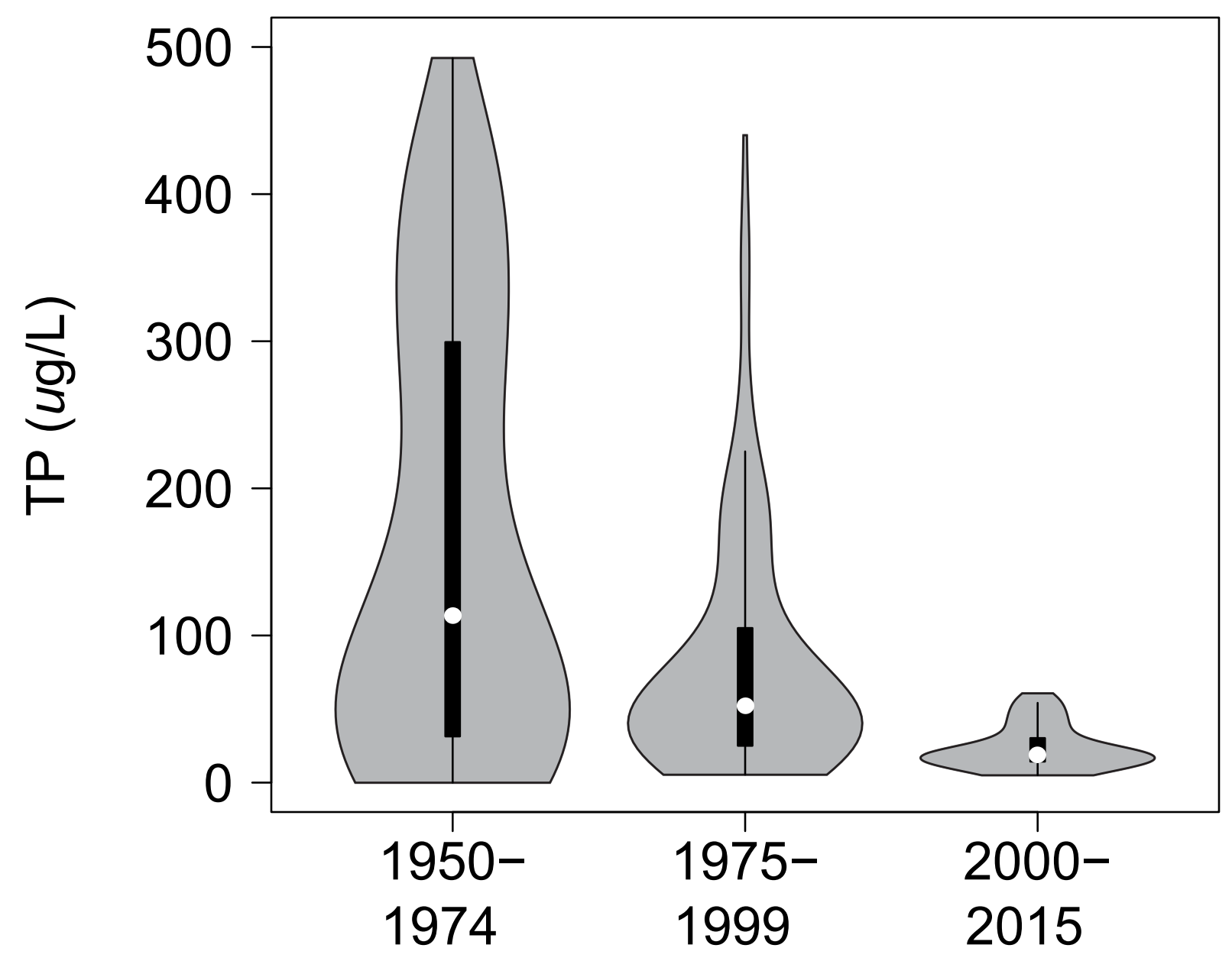


f

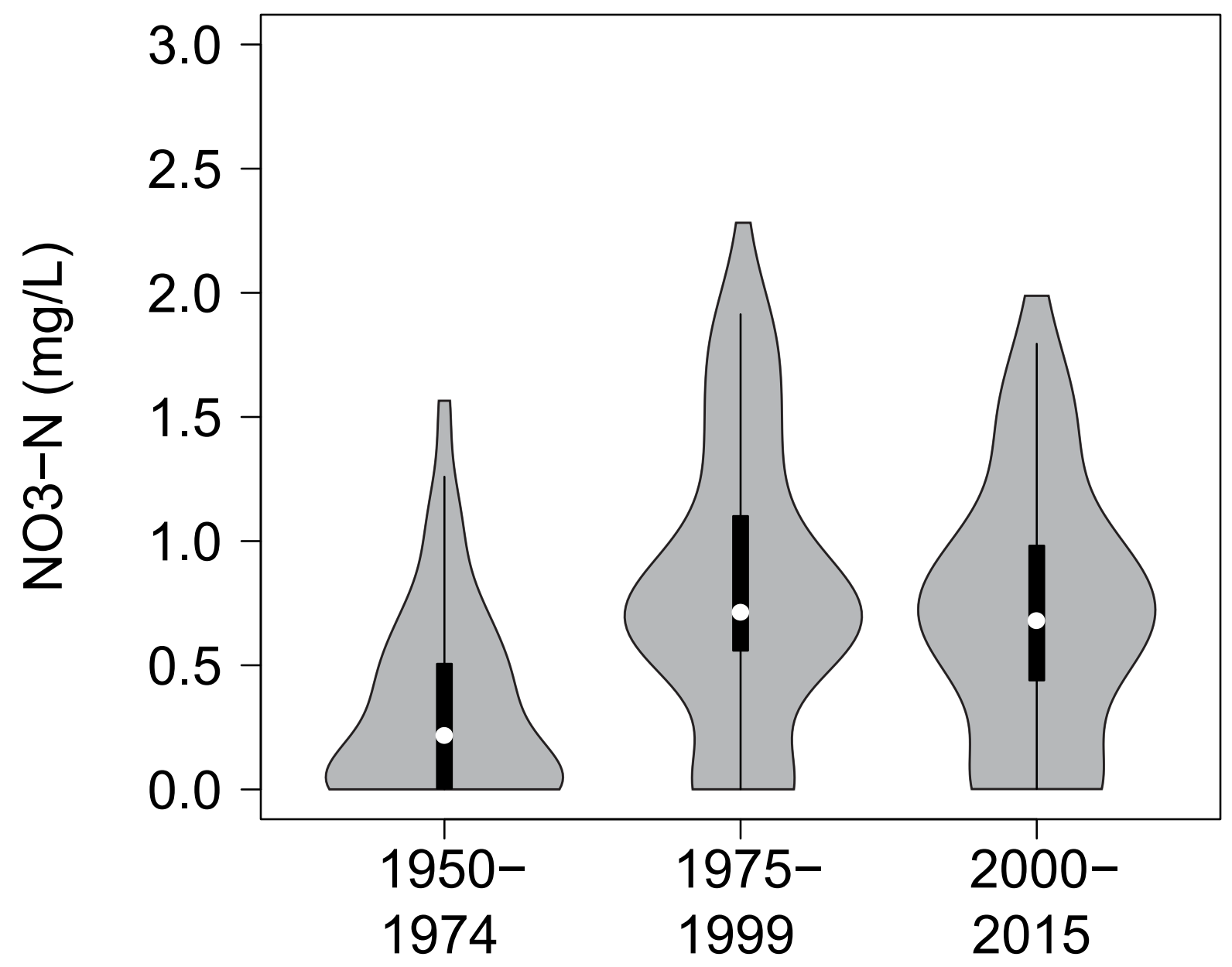




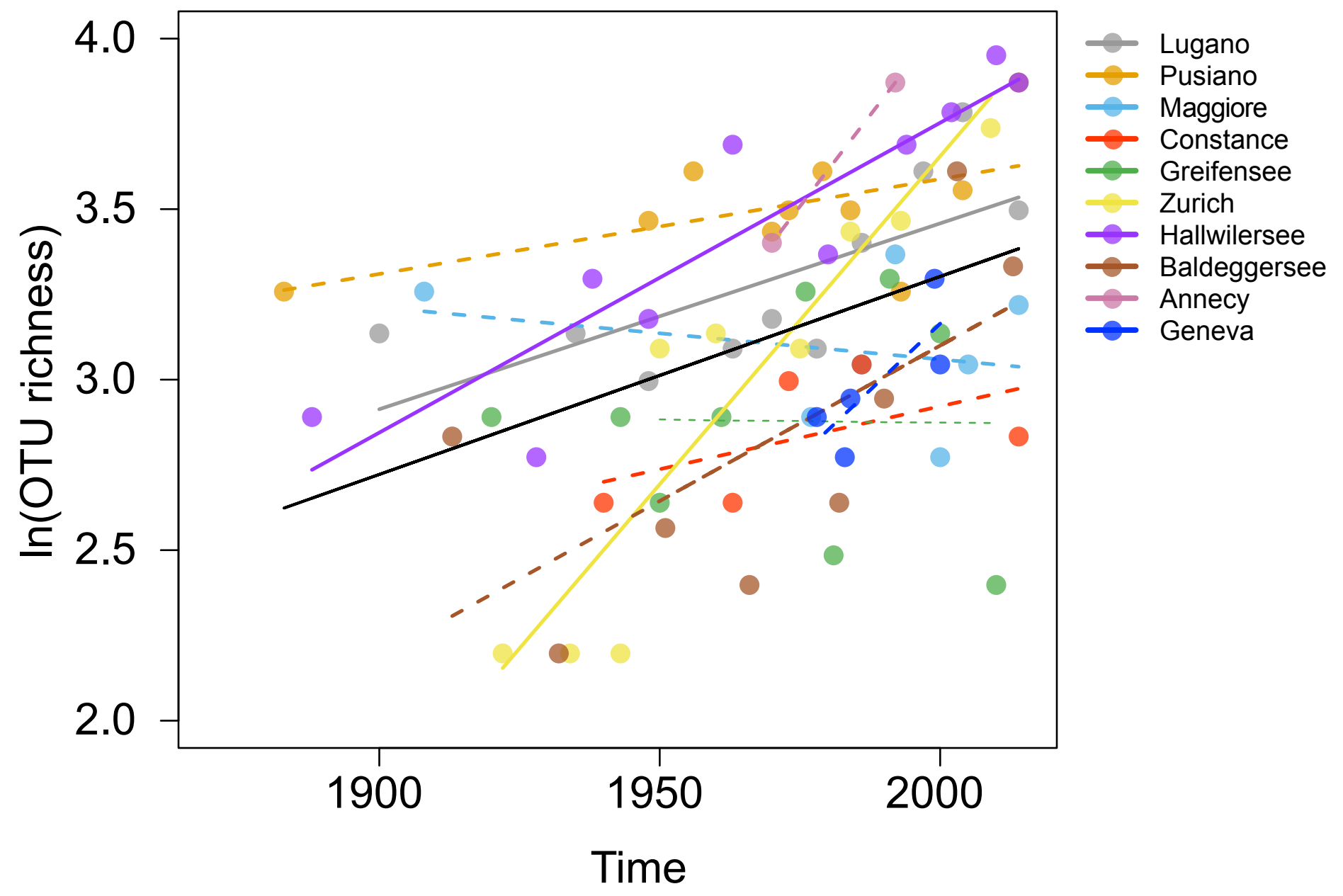


b

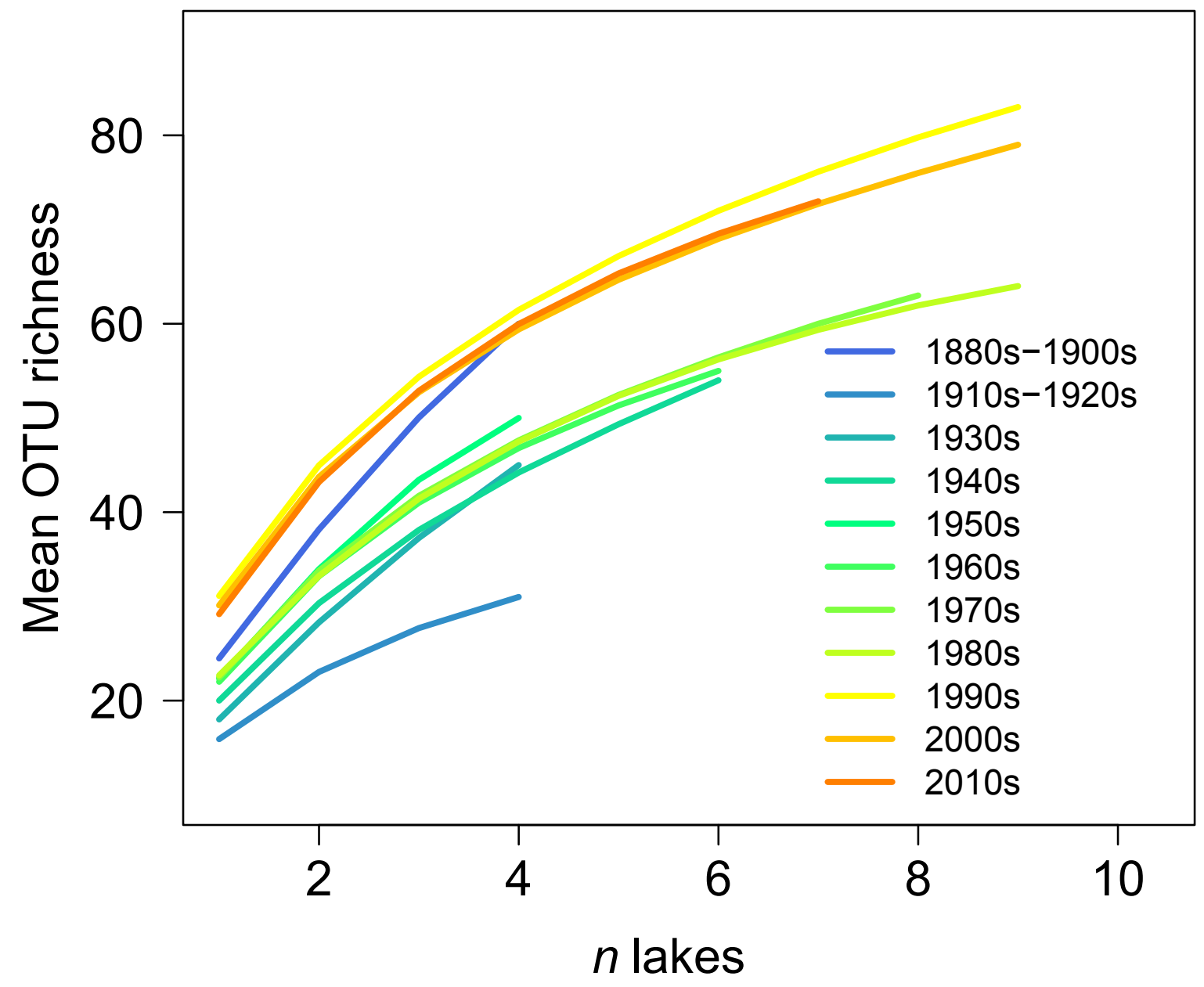




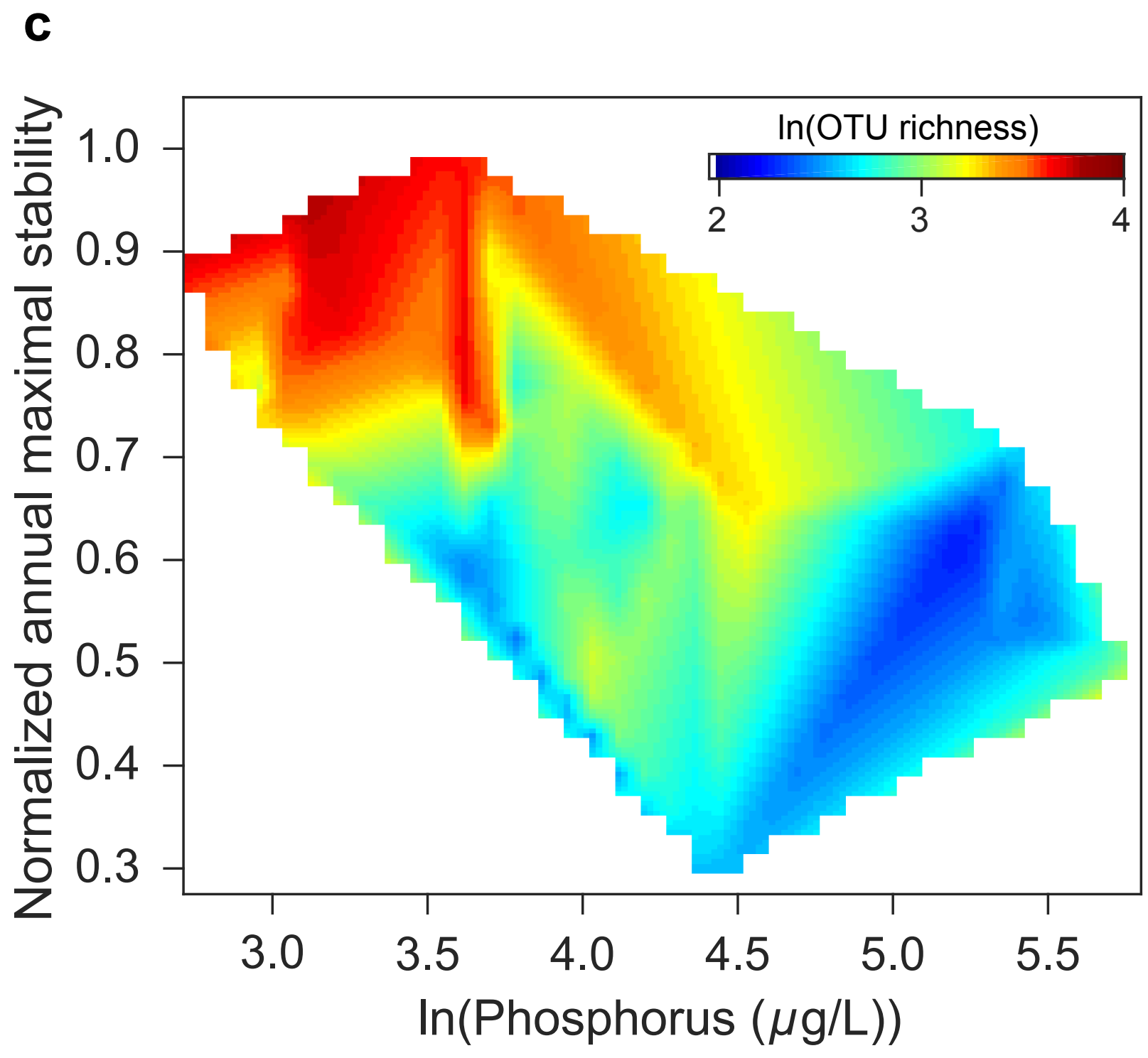




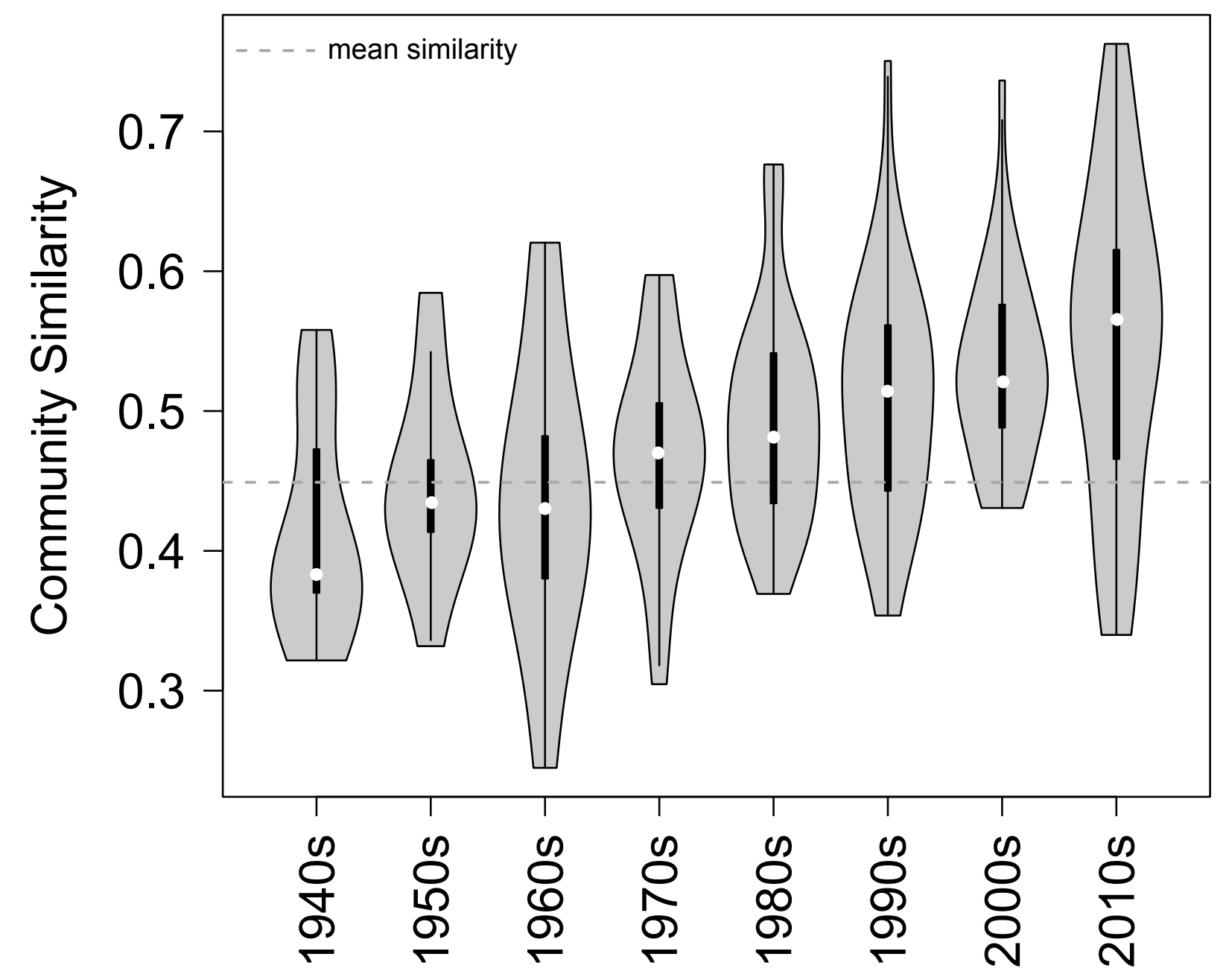




\section{Warming}

\section{Eutrophication}

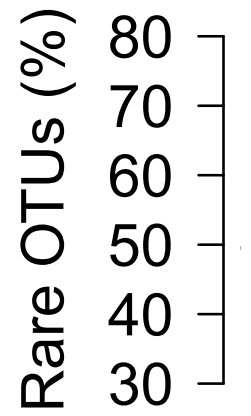

$n$ lakes $=10$

9

10

5

9

10

9

อ

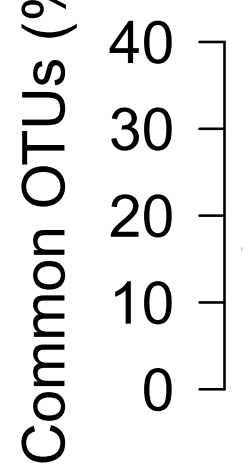

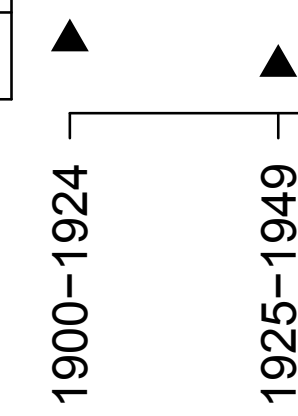

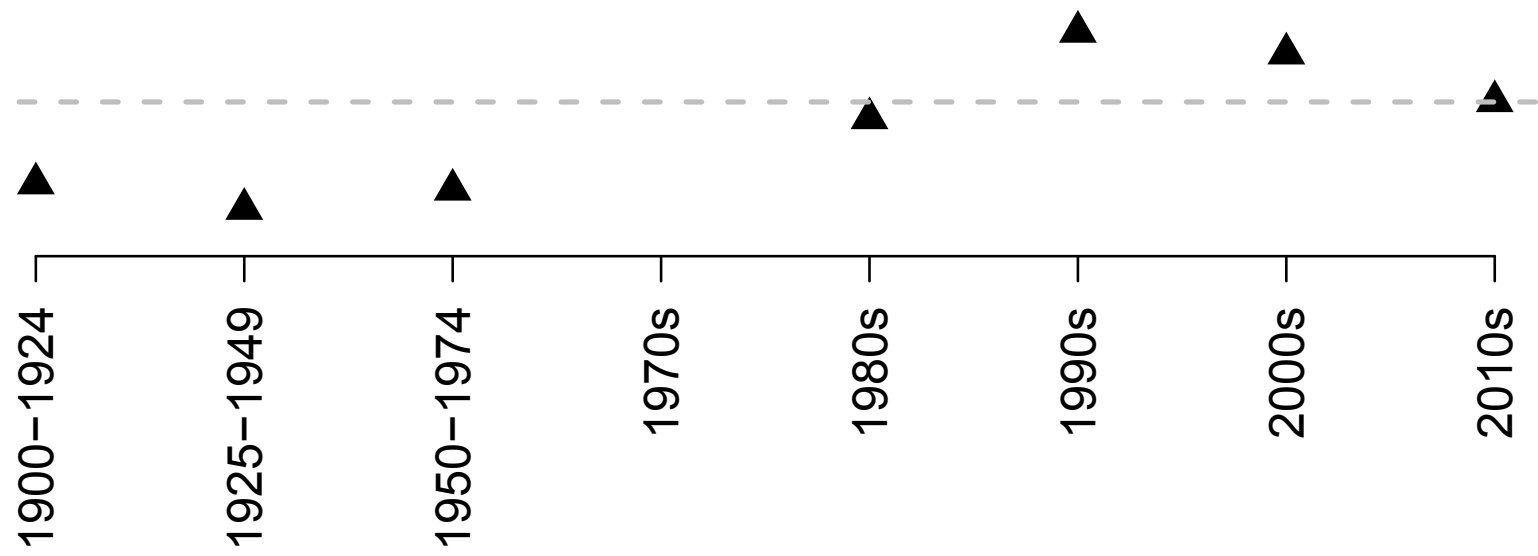

$\Delta$

Time period 

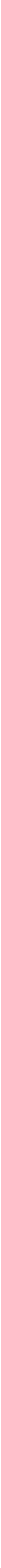


$$
\text { Lake Annecy } \bullet \text { Constance } \bullet \text { Greifensee } \bullet \text { Lugano } \bullet \text { Pusiano }
$$


